\title{
Socioeconomic status and risk of multiple myeloma
}

\author{
J MARTIN JOHNSTON, ${ }^{1}$ SEYMOUR GRUFFERMAN, ${ }^{2}$ CLAIRE C BOURGUET, \\ ELIZABETH DELZELL, ${ }^{2}$ ELIZABETH R DELONG, ${ }^{2}$ AND HARVEY J COHEN ${ }^{2}$
}

From the Department of Pediatrics, ${ }^{1}$ Duke Comprehensive Cancer Center, ${ }^{2}$ Duke University Medical Center, Durham, NC 27710, USA

SUMMARY A case control study was conducted to test the hypothesis that socioeconomic status is positively associated with multiple myeloma incidence. One hundred and fifty-three myeloma cases and 459 controls were identified at the Duke University Medical Center at Durham, North Carolina. Study members were interviewed regarding indicators of socioeconomic status. The association of myeloma with family income (current and highest), education, occupation, home ownership, dwelling size, and an index of crowding in the home was examined by estimating relative risks. Among these indicators, only home ownership showed any association with multiple myeloma incidence $(\mathrm{RR}=1 \cdot 6,95 \% \mathrm{CI}: 1 \cdot 0-2 \cdot 6)$. The association of multiple myeloma with socioeconomic status that has been seen in earlier studies may have been due to underascertainment of disease in less advantaged groups. This association is disappearing as access to health care becomes more uniform across socioeconomic groups.

In 1966, MacMahon noted a positive association of multiple myeloma mortality with social class as defined by occupation. ${ }^{1}$ Using mortality statistics of England and Wales for 1949-53, standardised mortality ratios for multiple myeloma were 188 for the highest and 76 for the lowest social class groups. Similarly, in the United States, Hoover et al used census data to show a slight positive association between the median educational level in a county and the county multiple myeloma mortality rates. ${ }^{2}$

However, the association of multiple myeloma with socioeconomic status is not seen consistently. Dawson and Ogston, investigating a high incidence of multiple myeloma in northeastern Scotland, found no difference between the social class distribution of their 153 patients and that of the population of Aberdeen or of the whole of Scotland. ${ }^{3}$ The Third National Cancer Survey showed no association of multiple myeloma with college education or with annual family income over $\$ 10000 .^{4}$ In a review of multiple myeloma data from 1950 to 1975 . Blattner et al noted somewhat higher mortality rates in state economic areas with residents of higher median income, although the trend was neither strong nor statistically significant. These authors did find a positive correlation between education and multiple myeloma mortality in whites..$^{5}$ More recently, Velez et al found a diminished social class gradient in multiple myeloma mortality for the period 1959-63 and no gradient for $1970-72$ in Great Britain. ${ }^{6}$

These conflicting reports of the relation between social class and multiple myeloma led us to examine indicators of socioeconomic status in a case-control study of multiple myeloma. We evaluated the hypothesis that individuals of higher socioeconomic status are at increased risk of developing multiple myeloma.

\section{Methods}

\section{STUDY MEMBERS}

We conducted a hospital based case control study of 153 patients with multiple myeloma and 459 matched controls. The study was intended to investigate several aspects of the epidemiology of multiple myeloma.

All multiple myeloma patients seen at the Duke University and Veterans Administration Hospitals of the Duke University Medical Center between June 1976 and May 1982, who met the diagnostic criteria of the Southeastern Cooperative Cancer Study Group ${ }^{7}$ were eligible for inclusion in the study. Cases were identified from outpatient appointment, inpatient daily census lists, and by attending physicians. Each case was matched to three controls on age (within a five-year interval), race, sex, 
hospital, date of admission, and inpatient/outpatient status. Patients on the psychiatry and intensive care services were excluded. Inpatient controls were selected from daily admission registers and outpatient controls from clinic appointment books. All study members were interviewed at the hospital. Interviewers were aware of the member's "case" or "control" status; however, they used a highly structured questionnaire. The interview included demographic data, occupation, residence, diet, and individual and family medical history.

Twenty-nine multiple myeloma cases who were eligible for the study were not interviewed. Comparison of these persons to other study members shows similar distributions of age, race, and inpatient/outpatient status but a different sex distribution (19 of 29 cases were women).

\section{INDICATORS OF SOCIOECONOMIC STATUS}

The following data were considered indicators of socioeconomic status: (1) current annual family income, categorised as \$0-9999, \$10-19 999, and $\$ 20000$ and above; (2) highest annual family income, similarly categorised; (3) years of education; (4) an occupational history, including job name and industry for up to ten separate jobs, plus the spouse's occupation at the time of interview; (5) home ownership; (6) the number of rooms and the number of occupants in the home $(a)$ during childhood, $(b)$ during adulthood, and $(c)$ at the time of interview.

\section{ANALYSIS}

The epidemiological measure of association calculated throughout is the ratio of the odds of higher socioeconomic status in cases versus controls. This odds ratio is used to estimate the relative risk of myeloma in higher versus lower socioeconomic status study members. We estimated the relative risk of myeloma for the following variables: (1) current and highest income; (2) years of education; (3) highest occupational rank; and (4) home ownership. Categories of occupational rank were based on the socioeconomic classification of occupation described by Guralnick.$^{8}$ For women, the husband's current occupation was also considered.

For each socioeconomic status indicator, the referent was the category presumed to indicate the lowest social class. Relative risks were estimated for the entire study population, and separately by race, sex, age, inpatient/outpatient status, and hospital, in order to examine possible effect modification by these factors.

We estimated unadjusted relative risk (ignoring the matching factors) and summary relative risk, using the method of Mantel and Haenszel to control for potential confounding by age, race, and sex. ${ }^{9}$
Confidence intervals for relative risk were calculated using a Taylor Series approximation of the variance ${ }^{10}$ or the test based procedure of Miettinen. ${ }^{11}$ For factors with orderable levels of exposure, two tailed significance tests for trend were calculated by the Mantel extension procedure. ${ }^{12}$ Finally, we performed multivariate analyses using a conditional logistic regression procedure.$^{13}$ In addition to the matching factors, occupational rank, years of education, highest income, crowding indices, and home ownership were included in the logistic model. The relative risks from the three analyses were very similar, and we report only the unadjusted relative risks.

In addition, means and standard deviations were computed for years of education, and for number of rooms in the home, number of persons in the household, and a "crowding index" (number of persons/number of rooms) at each of the three points in time described above.

\section{Results}

The race sex distribution of the study members is the following: $216(35 \%)$ white males; $156(25 \%)$ white ov females; $168(27 \%)$ black males; and $72(12 \%)$ blac露 은 females. Three hundred and seventeen $(52 \%)$ of the study members were younger than 65 years of age as $ᄃ$ the time of case diagnosis, and the remaining 298 $(48 \%)$ were older than 65 . Four hundred and eight $\overrightarrow{0}$ $(78 \%)$ had been seen at Duke Hospital and the remaining $132(22 \%)$ had been seen at the $V A$ Hospital. Two hundred and sixty $(42 \%)$ were inpatients and the remaining $352(58 \%)$ were outpatients.

The table shows the relative risk of myeloma for different levels of education, occupational rank, highest income, current income, and home ownership. Only occupational rank and home ownership show any association with multiple myeloma. There are no meaningful differences between cases and controls on years of education, number of rooms or number of occupants in the home, or crowding index using bivariate analysis; nor does multivariate analysis show any association of multiple myeloma with these factors.

Although the relative risks for some of the socioeconomic status indicators vary by age, race, 의 sex, and hospital, no one subgroup of subjects demonstrates a consistent association of multiple myeloma with multiple socioeconomic status indicators. Data for most categories of these $\sigma$ potential effect modifiers are sparse, and observed differences among subgroups appear to be chance findings.

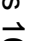


Relative risk of multiple myeloma associated with indicators of socioeconomic status (SES)

\begin{tabular}{|c|c|c|c|c|}
\hline SES indicator & $\begin{array}{l}\text { No of } \\
\text { cases/ } \\
\text { controls* }\end{array}$ & $\begin{array}{l}\text { Relative } \\
\text { risk }\end{array}$ & $95 \%, C I$ & $\begin{array}{l}\text { Mantel } \\
\text { extension } \\
\text { test } x^{2} \div\end{array}$ \\
\hline \multicolumn{5}{|c|}{ Years of education: } \\
\hline $1-8$ & $66 / 199$ & $1 \cdot 0$ & & \\
\hline $9-12$ & $45 / 146$ & 0.9 & $0.6-1.4$ & \\
\hline $13+$ & $42 / 114$ & $1 \cdot 1$ & $0 \cdot 7-1 \cdot 7$ & 0.39 \\
\hline \multicolumn{5}{|c|}{ Occupational rank: $\hat{\psi}$} \\
\hline $4-6$ & $48 / 166$ & $1 \cdot 0$ & & \\
\hline 3 & $49 / 157$ & $1 \cdot 1$ & $0.7-1 \cdot 7$ & \\
\hline 2 & $43 / 106$ & 1.4 & $0.9-3.2$ & \\
\hline 1 & $13 / 30$ & $1 \cdot 5$ & $0 \cdot 7-3 \cdot 1$ & $1 \cdot 72$ \\
\hline \multicolumn{5}{|l|}{ Highest income: } \\
\hline \$o-9999 & $42 / 144$ & $1 \cdot 0$ & & \\
\hline$\$ 10-19999$ & $47 / 116$ & 1.4 & $0 \cdot 9-2 \cdot 3$ & \\
\hline$\$ 20000+$ & $30 / 19$ & 0.9 & $0.5-1 \cdot 5$ & -0.75 \\
\hline \multicolumn{5}{|c|}{ Current income: } \\
\hline \$0-9999 & $75 / 230$ & $1 \cdot 0$ & & \\
\hline$\$ 10-19999$ & $31 / 86$ & $1 \cdot 1$ & $0 \cdot 7-1 \cdot 8$ & \\
\hline$\$ 20000+$ & $24 / 85$ & 0.9 & $0 \cdot 5-1 \cdot 5$ & -0.32 \\
\hline \multicolumn{5}{|c|}{ Home ownership: } \\
\hline No & $26 / 113$ & $1 \cdot 0$ & & \\
\hline Yes & $103 / 274$ & 1.6 & $1 \cdot 0-2 \cdot 6$ & \\
\hline
\end{tabular}

*Totals correspond to number of subjects responding to a given question.

$\doteqdot$ The sign of the chi indicates the direction of the trend.

$\uparrow 1=$ professional, 2 = technical/administrative/managerial,

$3=$ clerical $/$ sales $/$ skilled, $4=$ semiskilled, $5=$ labourer, $6=$ agricultural.

Stratifying by inpatient/outpatient status showed that the association of occupational rank with multiple myeloma is limited to outpatients. In that group, the relative risks for ranks 3,2 , and 1 compared to ranks 4 to 6 are $1 \cdot 1,1 \cdot 9$, and 2.0 respectively. The Mantel-Haenszel chi square statistic for trend is 2.36 with a probability of 0.02 .

\section{Discussion}

We have evaluated the relation between multiple myeloma and social class, using data from a case control study of multiple myeloma. Overall the results of the present study do not support the hypothesis that higher socioeconomic status is associated with increased risk of multiple myeloma.

Home ownership is the only socioeconomic status indicator which shows a positive association with multiple myeloma; however, the relative risk of 1.6 for home ownership versus home rental is not high and is of marginal statistical significance. There is a dose response relation of increasing multiple myeloma risk with increasing occupational rank. However, the relation is not strong and could occur by chance. This relation is statistically significant only among outpatients.
Examination of the data reveals that, for multiple myeloma cases at our institution, occupational rank is not a determinant of hospitalisation. For controls, however, occupational rank is positively associated with hospitalisation. Because inpatients are generally more acutely ill than outpatients, it is likely that socioeconomic selection forces would have less weight among inpatients. Therefore inpatient controls may be more representative of the general population than outpatient controls. Under this assumption we conclude that there is no real association of multiple myeloma with occupational rank and that the apparent association among outpatients is a result of selection factors. When other socioeconomic status indicators are examined, the differences between inpatients and outpatients are negligible.

MacMahon first noted the "epidemiological puzzle" posed by his observation that, while there is a positive association of multiple myeloma with social class, multiple myeloma is more common among nonwhites than among whites in the US. In fact, multiple myeloma incidence is at least twice as high among blacks as among whites, for both sexes and for almost all age groups. ${ }^{14} \mathrm{~A}$ review of the literature since MacMahon's article, however, raises doubts about the strength and interpretation of the association of multiple myeloma with socioeconomic status.

While Hoover et al observed higher mortality from multiple myeloma in the top $10 \%$ social class ranked US counties relative to the bottom $10 \%,{ }^{2}$ the age adjusted relative risks were only 1.4 for both males and females. Furthermore, as noted by the authors, there was a possibility of confounding by urbanisation, so that the relative risk could be overestimated.

A gradual disappearance of the socioeconomic gradient in multiple myeloma mortality in England and Wales has been reported. ${ }^{6}$ An examination of cancer statistics from Texas ${ }^{15}$ indicates a slower increase in multiple myeloma incidence among whites than among the more socially disadvantaged nonwhite and Spanish populations. This finding supports the hypothesis that the apparent socioeconomic gradient in multiple myeloma mortality results from underascertainment in lower social classes, a factor that is becoming less important as access to medical care becomes less dependent on wealth. An analogous argument has been advanced to explain the increasing incidence of multiple myeloma in the United States and in England and Wales. ${ }^{616}$ These increases are seen mainly in older age groups and are consistent with an age dependent improvement in diagnosis of multiple myeloma. 
Data from the present study are consistent with findings from earlier studies that any association of multiple myeloma with socioeconomic status is weak and entirely dependent on the socioeconomic status indicator employed. In conclusion, it appears that there is neither a striking nor a consistent association of multiple myeloma with socioeconomic status.

This study was funded by Public Health Service grants RO1 CA22104 and P30 CA14236 from the National Cancer Institute and by a grant from the American Family Corporation. SG was the recipient of a Preventive Oncology Academic Award K07 CA00726 from the National Cancer Institute.

Reprint requests to: Dr S Grufferman, PO Box 3958, Duke University Medical Center, Durham, NC 27710, USA

\section{References}

${ }^{1}$ MacMahon B. Epidemiology of Hodgkin's disease. Cancer Res 1966; 26: 1189-1200.

${ }^{2}$ Hoover RN, Mason TJ, McKay FW, Fraumeni JF Jr. Geographic patterns of cancer mortality in the United States. In Fraumeni JF Jr, ed. Persons at high risk of cancer: An approach to cancer etiology and control. New York: Academic Press, 1975, 343-60.

${ }^{3}$ Dawson AA, Ogston D. High incidence of myelomatosis in northeast Scotland. Scot Med J 1973; 18: 75-7.

${ }^{4}$ Williams RR, Horm JW. Association of cancer sites with tobacco and alcohol consumption and socioeconomic status of patients: Interview study from the Third National Cancer Survey. JNCI 1977; 58: 525-47.
${ }^{5}$ Blattner WA, Blair A, Mason TJ. Multiple myeloma in the United States, 1950-1975. Cancer 1981; 48: 2547-54.

${ }^{6}$ Velez R, Beral V, Cuzick J. Increasing trends of multiple myeloma mortality in England and Wales: 1950-1979; Are the changes real? JNCI 1982; 69: 387-92.

${ }^{7}$ Committee of the Chronic Leukemia-Myeloma Task Force. National Cancer Institute: Proposed guidelines for protocol studies. Cancer Chemother Rep, Part $3 \mathrm{~T}$ 1968; 3: 13-39.

${ }^{8}$ Guralnick L. Mortality by industry and cause of death among men 20 to 64 years of age: United States, 1950. Vital Stat Spec Rep 1963; 53: 439-44.

${ }^{9}$ Mantel N, Haenszel W. Statistical aspects of the analysis of data from retrospective studies of disease. JNCI 1959; 22: 719-48.

${ }^{10}$ Kleinbaum DG, Kupper LL, Morgenstern H. Epidemiologic research. Principles and quantitative methods. Belmont, Calif: Lifetime Learning Publ, 1982.

${ }^{11}$ Miettinen OS. Estimability and estimation in case-referent studies. Am J Epidemiol 1976; 103: 226-35.

${ }^{12}$ Mantel N. Chi-square tests with one degree of freedom; extensions of the Mantel-Haenszel procedure.J Am Stat Assoc 1963; 58: 690-700.

${ }^{13}$ Breslow NE, Day NE. Statistical methods in cancer research, Volume 1-The analysis of case-control studies. Lyon: International Agency for Research on Cancer, 1980.

${ }^{14}$ Cutler SJ, Young JL. Third National Cancer Surve Tu

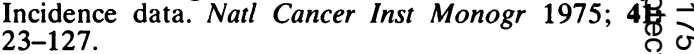

${ }^{15}$ McDonald EJ, Heinze EB. Epidemiology of cancer Texas: incidence analyzed by type, ethnic group, ang geographic location. New York: Raven Press, 197 213-5.

${ }^{16}$ Turesson I, Zettervall O, Cuzick J, Waldenstrom J\& Velez R. Comparison of trends in the incidence of multiple myeloma in Malmo, Sweden, and other. countries, 1950-1979. N Engl J. Med 1984; 310: 421-4: o 